\title{
Solar Radiation
}

\author{
New Evidence on the Intensity of Radiation Outside the Atmosphere
}

\author{
By C. G. Abbot, F. E. Fowle, and L. B. Aldrich
}

IN Volume III of the Annals of the Astrophysical Observatory of the Smithsonian Institution, we published the methods employed, the apparatus used, and results obtained in determinations of the mean intensit of solar radiation outside the atmosphere during the years 1902 to 1912 . The method employed was that of Langley. It requires measuring the intensity of the total radiation of the sun with the pyrheliometer and also the measurement of the intensity of the rays of the different wave-lengths with the spectro-bolometer. Measurements of both kinds are made repeatedly during a clear forenoon or afternoon from the time whe the sun is low untll it becomes high or vice versa. I this way we determine how rapidly the rays of the sun as a whole and of individual wave-lengths in particular increase in intensity as their path in air diminishes. From this we estimate the total intensity of the solar radiation outside the atmosphere altogether.

There are certain parts of the spectrum where by reason of powerful selective absorption of rays by water vapor and other terrestrial atmospheric vapors and gases, sufficiently accurate atmospheric transmission coefficients cannot be determined in this manner." This offers no great difficulty, for, with Langley, we assume that these absorption bands would be absent outside the atmosphere. Hence, the intensity of these parts of the spectrum outside the atmosphere can be determined by interpolation from the intensities found on either side of them.

Whatever the value of the atmospheric extinction of solar rays, all good solar constant work depends on accurate pyrheliometry expressed in standard calories. During the investigation we devised two forms of standard pyrheliometer on quite different principles. These instruments agree with each other to within 0.5 per cent, and they yield values of the solar radiation ranging frow 3 to 4 per cent above those found with different coples of the Angström pyrheliometer. This latter instrument was adopted as the internationil standard for the measurement of radiation by the meeting of the International Meteorological Committee held at Southport in the year 1903 and by the International Union for Solar Research at its meeting at Oxford in the year 1905 . Mr. A. K. Angström has, however, lately the year 1905 . Mr. A. K. Angström has, hovever, latel. slight errors which cause it to read about 2 per cent too low, according to his opinion. If so, this brings the scale of the Angström within less than 2 per cent of the scale of the Smithsonian Institution. The latter scale is fortified by the fact that in our several standard pyrheliometers it is possible to introduce and determine test quantities of heat. This has been repeatedly done in each of these instruments, and the test quantities of heat have been recovered to within 0.5 per cent

The following table gives the results of nearly seven hundred measurements of the solar constant of radiation as published in Volume III of the Annals above cited :

\begin{tabular}{l} 
TABLE 1-Mrean Solar Radiation Ontside the Atmosphere \\
Expressed in standard $15^{\circ}$ calories per square centimeter per minute at mean \\
solar distance \\
\hline Station \\
\hline
\end{tabular}

The Washington results fall a little higher than the others. This may be due, in part at least, to the fact that most of them were made while sunspots wer numerous, for our investigations at Mount Wilson indicate that high values prevall when sunspots are at a maximum.

Our determinations rest on the assumption that for all excellent days the atmosphere may be regarded without sensible error as made up of layers, concentric with the earth, which may differ in transparency from layer to layer in any gradual manner, but which, within - Notes from Bmithsonian Miscellaneous Collections, Vol 65, No. 4

1 "Report on the Mount Whitney Expedition," Professlona Papers, Signa

'Investigations of Fowle showed, however, that transmis sion coefficients can be obtained even in the great infra-red bands of water vapor, whose employment would practically
obliterate the bands outside the atmosphere. Hence, we may conclude that if there are difuse atmospherlc bands not easily recognizable, they will be almost exactly allowed for by ordinary tra
Vol. 47. the time and sunce covered by a solar beam during a ingle morning of observation, are for each laver by self sensibly of uniform transparency. As the relaive transparency of the several layers is not assumed to be known, it is convenient to limit the duration of a single series of observations to the time interval during which the solar zenith distance is less than 75 degrees. During this interval the rate of decrease of path of the solar beam in the atmosphere, with decreasing solar zenith distance, is sensibly the same in all the supposed atmospheric layers, and is proportional to the change of the secant of the zenith distance. For greater zenith distances than these this proportionality does not hold, because the influences of curvature of the earth and of tmospheric refraction.

A variety of conditions of observation were encountered; first, as regarding the intensity of sunlight at the observing station; second, as to the effect of atmospheric humidity on the infra-red spectrum; third, as to the effect of dust upon the visible spectrum. We draw attention to the close agreement of the solar constant values obtained in these contrasting circumstances of observation.

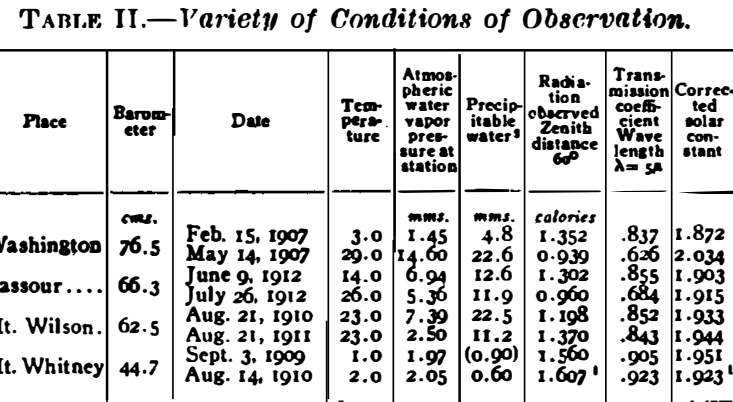

From the foregoing the reader may see that the soundness of the theory of the atmosphere extinction of radiation employed by us is supported by the fact that its application to observations malde under widely diverse conditions ylelds nearly identical values of the intensity of solar radiation outside the atmosphere. Nevertheless, it is maintained by some critics that ou estimate of the atmospheric extinction is less than half large enough.

In further support of our values of atmospherfc transIssion, we call attention to their connection with Lord and particles small as compared with the wave-length of light. According to this the exponent of scatterin varies inversely as the fourth power of the wave-length and thus the product of fourth power of wave-length by logarithm of transmission coefficient should be constant. $\Lambda \mathrm{s}$ shown by one of us, ${ }^{2}$ the coefficients of atmospheric transmission obtained on Mount Wilso depend slightly on the total atmospheric humidity in cluded between Mount Wilson and the sun. The transmission coetficients may be reduced to dry air condition by applying a very small correction to them. These corrected coefficients are found to be in close harmony with Lord Rayleigh's theory.

13y the aid of Lord Rayleigh's theory of the scatte ing of light, Mr. Fowle has determined from the Mount Wilson experiments the number of molecules per cubic centimeter of dry air at standard temperature and pressure. Ile finds the value $(2.70+0.02) \times 10^{10}$, while Mil likan obtained, by wholly dissimilar methods, (2 705 $0.005) \times 10^{19}$

In the course of our experiments at Mount Wilson, we found the solar radiation outside the atmospher variable in short irregular periods of from five to te dass, and to have a variable range of from 2 to 10 pe cent. That this variability is really solar was confirmed by independent simultaneous observing at Bassour. in Algeria, and still more recently by as yet un jublished experiments on the distribution of brightne over the sun's disk. This latter method is quite independent of atmospheric disturbances. It seems to that if our solar constant results were erroneous to the extent that the solar constant is really 3.5 calories instend of 1.03 , as some of our critics would persuade us

${ }^{1}$ This value is corrected as suggested In note 2 , Annals II page 113.

1)eterminel hy Fowle's spectroscopic methol, and gives th depth of liquid water which would result if all the atmo Txperiments of 1913 show ts results with those ohtalned for the same days by integra tion of humldity ohserved at all altitudes by sounding balloons
i F. E. Fowle, Astrophysical Journal, 38, 392, 1913; 40, 435, 1914 the probability of finding these real solar variations of 2 to 10 per cent by simultıneous observing at stations separated by one third of the circumference of the earth would be very small. We should suppose that if there are atmospheric conditions which lead to our underestimating by nearly 50 per cent the intensity of solar rudiation outside the atmosphere, these would probably be variable from day to day; so that such minute real changes of the total intensity of the sun's radiation as we have found would have been swallowed up in the irregular local fluctuations of the transparency of the atmosphere.

Nearly all the pyrheliometry now being done in the world is done with Angström, Marvin, Michelson, or Smithsonian pyrheliometers. These represent five independent attempts to fix the standard scale of radiation. They have been many times compared with each other, and are found to accord within less than 4 per cent, and now, in view of $A$. K. Angström's resenrches, perhaps to less than 2 per cent. Of these scales of pyrheliometry, ours gives the highest readings. We have devoted much experimenting during many years to the establishment of the standard scale of pyrhelimetry. Many observers reduce readings obtained with other pyrheliometers to the Smithsonian scale. Dr. Hellmann has indeed gune so fir as to say publicly" that there is but one standard pyrheliometer, and that is at the $\Lambda$ strophysical Observatory of the Smithsonian Insti$\Lambda$ strophys
tution.

COMPARATIVE RESULTS OF PTRHELIOMETRY AT REDUCED ATMOSPHERIC PRESBURES.

In a recent publication, l'ror. $H$. $H$. Kimball gives the highest value of solar radiation ever observed at Washington, for zenith distance 60 degrees, as 1.51 calories per centimeter ${ }^{2}$ per minute, observed on December 26th, 1914. Reduced to vertical sun and mean solar distance, 1914. Reduced to vertical sun and mean solar dista
thls result would have been about 1.58 calories.

The highest values observed on Mount Wilson are those of November :ind, 19:(n), and vield to a similar reduction 1.64 calories, at mean solar distance and vertical sun.

For Mount Whitney, for the maximum obtained on Septemler 3rd, 1969, the reduced value is 1.72 calories at mean solar distance and vertical sun.

In balloon flights of August 31st, September 25th, and October 19th, 1913, Dr. A. Peppler of Giessen observed with an Angström pyrheliometer at great altitudes. Or September 2 sth the results were, in his opinion, vitiated by a defect of the apparatus. On August 31st, the highest result, as reduced by Peppler to the Smithsonian scale of pyrheliometry, was 1.77 calories, obtained at zenith-distance 45 degrees, altitude 5,000 meters, air iressure 36.5 centimeters. This result, hovever, is not a complete Angström measurement delending on "left. right, left" readings, and therefore may be vitiated by galvanometer drift. Moreover, it stands very high as compared with others of that date, and, indeed, much higher than others of that date obtained at greater altitudes. On October 19th, the highest complete result was 1.67 calories, obtained at zenith distance 61 degrees, altitude 7,500 meters, air pressure 29.3 centimeters. This result is in good agreement with the others of that date. P'eppler regards the results of October 19th as his best. When reduced to zenith sun and mean solar distance, the result of October 19th comes out about 1.755 calories per centimeter per minute.

These direct observations from manned balloons are very meritorious, and of course entitled to far greater weight than those obtained at similar altitudes in our free balloon work at Avalon, in 1913 . Hence, although our results there were in complete accord with Peppler's, we have not thought it worth while to give them. It seems to us that, with the complete accord now reached letween solar constant values obtained by the slectro-bolometric method of Langley, applied nearly one thousand times in ten years, at four stations ranging from sea level to 4,420 meters, and from the Pacific Ocean to the Sahara Desert; with alr-masses ranging from 1.1 to 20 ; with atmospheric humidity ranging from 0.6 to 22.6 millimeters of precipitable water; with temperatures ranging from 0 deg. to 30 deg. Cent.; with sky transparency ranging from the glorious dark blue above Mount Whitney to the murky whiteness of the volcanic ash filling the sky above Bassour in 1912, it was superfluous to require additional evidence.

But new proofs are cited above. These give the re Bericht ther die Frste Tagang der Strahlungakommlsslo des Internatlonalen Meteorolosiscben Komlten is Bapperengl
bes Zuricb, 2 8eptemher, 1912. 
sults of an independent method of solar constant investigation. In this method the observer, starting from sea level, measures the solar radiation at highest sun under the most favorable circumstances, and advance from one level to another, until he stands on the highest practicable mountain peak. Thence he ascends in a balloon to the highest level at which a man may live. Finally, he commits his instrument to a free balloon, and launches it to record automatically the solar radiation as high as balloons may rise, and where the atmos lheric pressure is reduced to the twenty-fifth part of its sea level value. All these observations have been made. They verify the former conclusion; for they indicate a value outside the atmosphere well within the previously ascertained limits of solar variation.

Our conclusion still is that the solar constant of radiation is 1.93 calories per square centimeter pir minute.

\section{Aerial Warfare and the Weather}

\section{Conditions That Affect Various Classes of Aircraft}

ALr trades carried on outdoors-and that of the fighting-man is no exception-are bound to keep a ver watchful eye on the weather. There are many famous in itances where the state of the weather has proved to be the deciding tactor that sit rout and onc side, and victory for the other. Some of the famous instances of this interposition of the elements have been the dispersal of the Greek fleet after the fall of Troy. the wreck of the Spanish Armada, and the failure of Napoleon's invasion of Russia.

Modern armies have means of combating adverse con ditions of the elements unknown earlier. But on the other hand, the present war has developed a new branc of the service - that of the aerial corps-which is peculiarly susceptible to interference by adverse condition of the weather. It is a very few years indeed since the most experienced airmen then existing would wait for hours before essaying flight till the wind was just right, though impatient crowds jeered at the delay. But amil the desperate chances that are the common place of a soldier's life the braving of the elements in a flimsy bit of wood and silk is frequently the less of two dangers.

As a result there has been much valuable information gained as to the way in which varying conditions of wind, temperature, etc, affect aircraft of different sorts. The subject is ably treated by Lieut. Metz of the German army in Umschau (Berlin) of June 17th. We read:

The war aircraft in use in the present movement comprise three principal kinds, the captive balloon, the dinigible airship, and the aeroplane, while the fre balloon has thus far not been employed. The captive balloon, which is used in all armies as an important means of observation-especially for the artillery-is nothing but a free balloon secured by a cable. But in the course of time, because it pulled and struggled at its ropes so much, so that its occupants suffered from seasickness, it has been given a longer form, with a air-bag at one end. This has given it a greater stability so that observation from it is possible even in quit high winds. It may be mentioned here that until shortly before the war the French gave preference to the suherical form for captive halloons. During the war, however, the German form appeared at important points. This can be imperilled chiefly by sudden gusts of wind, which break its cable, a particularly unpleas ant accident, since this usually throws important secre olservations into the hands of the enemy.

Far more important are storm conditions to a dirig ible. While in general the climatic conditions of a country, known by years of observation, are of decided significance, and the equipment and care of troops, ete must be governed by them, in many cases a condition of storm which suddenly arises, or a sudden change of weather may be decisive factors in determining the result of military operations. Slight as such a thing may appear in the records of meteorologists and clime tologists, it may be of violent effect on the activities the air the spite of all progress in this direction is sufficiently proved by the catastrophies to many of our marine airships on the Danish coast around the period of the equinox

The dangers that mas accrue to an uirship from bad weather comprise varions factors, according to Lieut. Metz. Thus an aerostat, i. e., a machine filled with gas lighter than air-in order to be of military use must not only be able to remain at such height as is required for a considerable length of time, but must also be able to return safely to its hangar. But at a height of from 1,500 to 2,000 meters $(4,875$ to 6,500 feet) a airship loses a great deal of gas, and temperature plays an important part here.

In warm air the gas in the ballonets expands. Ever one has observed that free halloons are not pumped full before they go up. In the higher strata of air the gas expands because of the lessened pressure. In course of time some gas escapes, and in order to maintain the same height it is necessary to throw out ballast. Thi does not apply exactly to motor-driven aircraft, however. Though gas to lost when travellng at high althtude, the steady consumption of tuel and the loss of weight due to the throwing of bombs permit of a long cruise at a great height without the discarding of much ballast. A degree of compensation for the expansion of the gas results also from the fall in temperature due to ascent, which equals about $0.5 \mathrm{deg}$. to $0.8 \mathrm{deg}$. Cent. for every 100 meters (328 feet). But change of temperature may always be a source of danger. If, for in stance, an airship rises in direct sunlight the gas may be warmed up to $40 \mathrm{deg}$. Cent.-and if this occurs at great heights a serious loss of gas is unavoidable.

If the airship does not return to its shed till after nightfall these may be the following result: The earth is much cooled, the warm air has risen, the dirigible

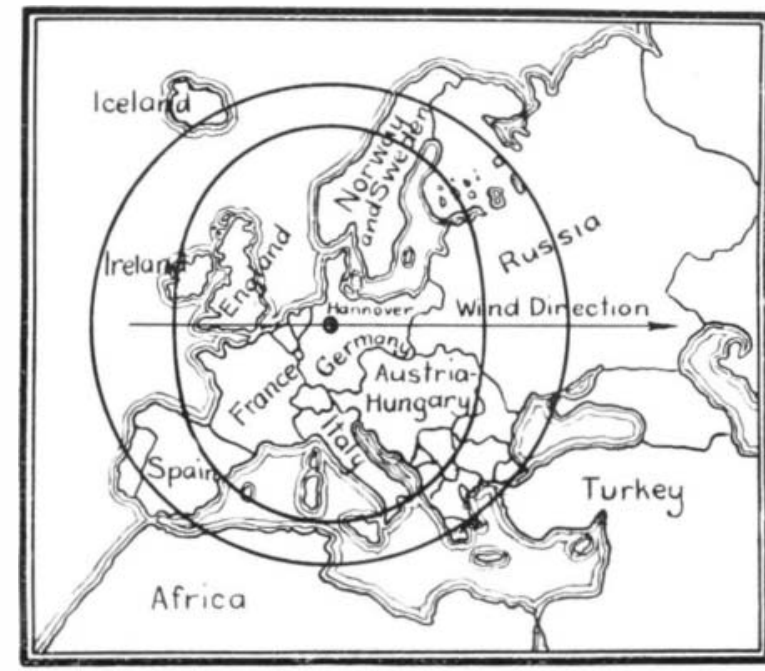

Radius of action of a modern airship with Hanover as a base. Outer circle in still air. Elipse with wind in direction of arrow.

comes on at normal speed and sags on entering the cooler layers of air because of the sudden contraction of the gas. If by an unlucky chance ballast is not thrown out fast enough, or the men below do not catch the ship, then the longitudinal ribs may be broken if no worse mishap befalls.

Obviously, therefore, it is best to ascend at end of night rather than vice versa, since as day advances the warmer air will expand the coolel gas and give it more lifting power. It is clear, too, that this circumstance is of the greatest importance in the nocturnal expeditions of our Zeppelins against England. Their success in the present warm season shows this view to be correct. This is equally true for all systems. Though there is no breaking of ribs in the non-rigid ships, the gondola with its valuable machinery may be destroyed.

Lieut. Metz next discusses the obvious difticulties of orientation at night and in obs cure weather caused by low-lying clouds, fog, rain and snow, but remarks that these very conditions favor safety in making raids and ease of escape from stronger and faster foes. Wind, too, is a great source of danger, but so long as the ship is in the air wind can do little harm unless it has greater velocity than the dirigible itself. In that case destruction is pretty certain. It also has an extremely unfavorable influence on the ship's radius of action. The accompanying map shows that while this "action radius" is a circle in still weather it becomes an ellipse in windy weather.

If a dirigible travels from $A$ to $B$-at say 288 kilometers apart-and it has a speed of 20 meters per second, then it will cover this distance in calm weather in about 4 hours. If there $\mathrm{s}$ a headwind of 10 meters per second then the ship will travel only 10 meters per second and will require 8 hours to cover the same distance. In the first case the return trip will take the same time as the outgoing journey. But with a ten-meter wind behind it the return trip can be made in 2 hours and 36 minutes. From this we see the advantage of having fast ships, since the weaker the ship the worse the effect of the wind.

One other danger may arise from wind, 1. e, when It is nerpendicular to the hangar. In such an event it is often Impossible to take the dirigible in or out of the house, and It must perforce be anchored. In such circumstances many Zeppelins have already been destroyed by the ship's back being broken, or its being torn loose from the cable. Ruin and suow burden an airship with tons, weighing it to the ground, or hurling it against hills and houses. A thunder-storm, too, may annihilate it and its crew by a stroke of lighting, even without this extremest misfortune the effect of such a storm is always to interrupt wireless communication with the land.

Lieut. Metz adds that the steady perfecting of the aeroplane, both -of the motor and of the construction, have made it almost independent of the weather. The success of the aviator depends on the faultless functioning of his motor, and weather can exert a decisive influence upon it only through severe cold.

\section{A New Mastodon}

THE preparators and aids in the section of Vertebrate Paleontology of the United States National Museum are busy putting together the bones and fragments of a huge skeleton of a mastodon recently secured near Winamac, Indiana, by the assistant curator of fossil mammals, Mr. James W. Gídley.

Nearly a year ago a mastodon skull and several other bones were dug up by a steam shovel is the course of constructing a drainage ditch in a swampy deposit on the farm of Messrs. H. H. and W. D. Pattison, several miles northwest of Winamac, Indiana. These bones were generously donated to the United States Nationa Museum by the Pattison Brothers, with the privilege of making further search if desired, and it was soon decilled that a further search would yteld valuable results. The remains of this monster were found in good condition, although near the surface, having lain without being disturbed for thousands of years in marly deposits of an ancient swamp.

A small appropriation was secured for further excavation in the locality of this find, with the result that Mr. Gidley has just returned with nearly all the othe bones of this gigantic mammal. Practically a complete keleton was found, except two large limb bones, many of the foot bones, and the tusks, for which a furthe search may soon be made. When mounted the Museum will possess one of the most complete specimens of this reat beast of the ages just preceding the present. There is a small mastodon specimen in the Museum collection secured in 1901 from the peat deposits near Church, Michigan, but the new one will overshadow it by over two feet in height and several hundred pounds in weight. It is helieved that this skeleton will stand full en feet high. The fine state of preservation of the bones is due to the fact that it has lain continuously since its entombment beneath the water level of the swamp, and thus has not been affected by the oxidizin action of the air. Mr. Gidley feels certain that with patience and by draining the ditch the missing portions of the skeleton will be found.

The sperimen is believed to be that of a full grown male, although not an old individual, who lived in the Pleistocene age, probably 150,000 years ago. This animal, while it is related to the elephant family, differs in general proportions of the skeleton and through the character of its teeth, which unlike the flat grindin ones of the elephant, are more of a rugose type with pointed corrugations calculated to have been used in crushing as well as grinding the coarse vegetable fool on which it lived. The largest of the teeth measure nearly seven inches in length and is about four inches across, weighing several pounds.

Prospects for continued excavation and search are promising, and Mr. Gidley with his corps of preparators are anxiously awaiting the time when the missing piece of their great puzzle $m$ ay be found and put in place.

\section{Testing Insulating Materials}

THE results of experiments indicates that the larger the surface of the plate electrode the smaller is the break down voltage in testing thin layers of insulation the explanation being that thin layers have weak spots which are more likely to be found by using large electrodes. An objection to the method ts the posslbility of alr between the electrode and insulator. 